\title{
DIRECT TORQUE CONTROL USING NEURAL NETWORK APPROACH
}

\author{
Suresh Kumar Chiluka ${ }^{1}$, S. Nagarjuna Chary ${ }^{2}$, E Chandra Mohan Goud ${ }^{3}$ \\ ${ }^{1,2,3}$ Asst. Professor, EIE, VNRVJIET, Hyderabad \\ skchiluka@gmail.com,nagarjunachary85@gmail.com,goudnitt@gmail.com
}

\begin{abstract}
Direct Torque Control (DTC) is one of the latest technique to control the speed of motor, in this paper, the control technique of DTC is based on when load changes then inverter switch position are changed and supply to the motor is changed, in this paper Proportional Integral (PI), Neural Network (NN) controller and Adaptive motor model is designed this is the heart of the DTC, as we know that DTC doesn't require any feedback and sensors to measure. The NN structure is to be implemented by input output (nonlinear) mapping models and is constructed with input, output and hidden layers of sigmoid activation functions. It has been introduced as a possible solution to the real multivariate interpolation problem. To improve the performance of DTC with the modern technique using NN approach is implemented, and performance of DTC with PI controller and NN controller is done, hence, the NN approach shows the better performance than conventional PI controller.
\end{abstract}

Keywords: DTC, PI, NN, Adaptive Motor Model and MATLAB.

\section{INTRODUCTION}

One of the main problems in induction motor speed control systems is the design of a stable speed controller against external disturbances, sudden load changes. Due to presence of these nonlinearities, it is not easy to design the mathematical models. For this soft computing approaches using a Recurrent Fuzzy Neural Network (RFNN) and Fuzzy Logic (FL) have been used for replacing numerical methods. In an RFNN observer for the unknown uncertainties was proposed, and showed superior performance results compared to the conventional approaches.

A robust adaptive speed sensor less induction motor with DTC using a neural network approach is implemented in this paper and the obtained result is compared with PI controlled result. The inherent lumped uncertainties of the induction motor DTC system such as parametric uncertainty, external load disturbance and unmodeled dynamics are approximated by the NN. An additional robust control term is introduced to compensate for the reconstruction error. A control law and adaptive laws for the weights in the $\mathrm{NN}$, as well as the bounding constant of the lumped uncertainties are established so that the whole closed-loop system is stable in the sense of Lyapunov. The effect of the speed estimation error is analyzed, and the stability proof of the control system is also proved. Experimental results as well as computer simulations are presented to show the validity and efficiency of the proposed system [1]. Although it is possible to achieve the ac motor's high level of speed control by the application of the trans-vector theory, the resulting controller becomes too complex to implement for a wide range of applications. An alternative to the trans-vector control is the direct torque control. Most of researchers are concerned with the inner loop for a torque control without taking in consideration the overall loop for the speed regulation. Also, fuzzy logic has been used with DTC to improve the dynamic performance of the induction motors [2]. DTC is the technology to control the "real" motor control variables like torque and flux.

The advantage of this technology is the fastest response time, elimination of feedback devices, reduced mechanical failure, performance nearly the same as the DC machine without feedback, etc.

\section{CONTROL METHODOLOGY \& OPERATION}

In normal operation, two motor phase currents and the DC bus voltage are simply measured, together with the inverter's switch positions[3]. The measured information from the motor is fed to the Adaptive Motor Model. The sophistication of this Motor Model allows precise data about the motor to be calculated. Before operating the DTC drive, the Motor Model is fed information about the motor, which is collected during a motor identification run.

This is called auto-tuning and data such as stator resistance, mutual inductance and saturation coefficients are determined along with the motor's inertia. The identification of motor model parameters can be done without rotating the motor shaft. This makes it easy to apply DTC technology also in the retrofits. The extremely fine tuning of motor model is achieved when the identification run also includes running the motor shaft for some seconds [4].

There is no need of feed back any shaft speed or position with tachometers or encoders. The Motor Model outputs control signals which directly represent actual motor torque and actual 
stator flux. Also shaft speed is calculated within the Motor Model. The information to control power switches is produced in the Torque and Flux Comparator. Both actual torque and actual flux are fed to the comparators where they are compared, to a torque and flux reference value. Torque and flux status signals are calculated using a two level hysteresis control method. These signals are then fed to the Optimum Pulse Selector. Within the Torque Reference Controller, the speed control output is limited by the torque limits and DC bus voltage. It also includes speed control for cases when an external torque signal is used. The internal torque reference from this block is fed to the Torque Comparator. The Speed Controller block consists both of a PI controller and an acceleration compensator. The external speed reference signal is compared to the actual speed produced in the Motor Model. The error signal is then fed to both the PI controller and the acceleration compensator. The output is the sum of outputs from both of them. An absolute value of stator flux can be given from the Flux Reference Controller to the Flux Comparator block. Later we approached NN Controller by replacing PI and compared the responses of both. Like this speed of the motor will be controlled in DTC [3\&4]. The Fig.1 shows the direct torque control method.

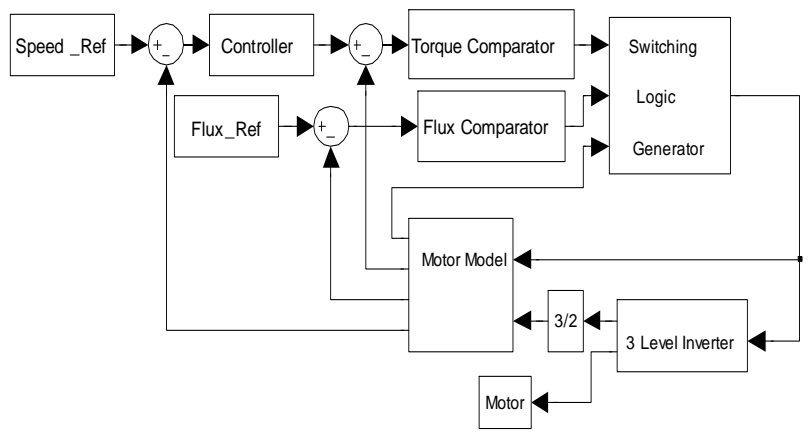

Fig 1: DTC Control Method

Using MATLAB simulation we designed DTC with controllers, the schematic of the functional block are shown in Fig: 2, it consists of three main blocks they are

1. Direct Torque Control(DTC)

2. Induction Machine Model

3. Controllers

In this work, we simulated the model with two controllers separately and compared the results with each controller. The controllers are

1. Proportional \& Integral Controller

2. Neural Network Controller

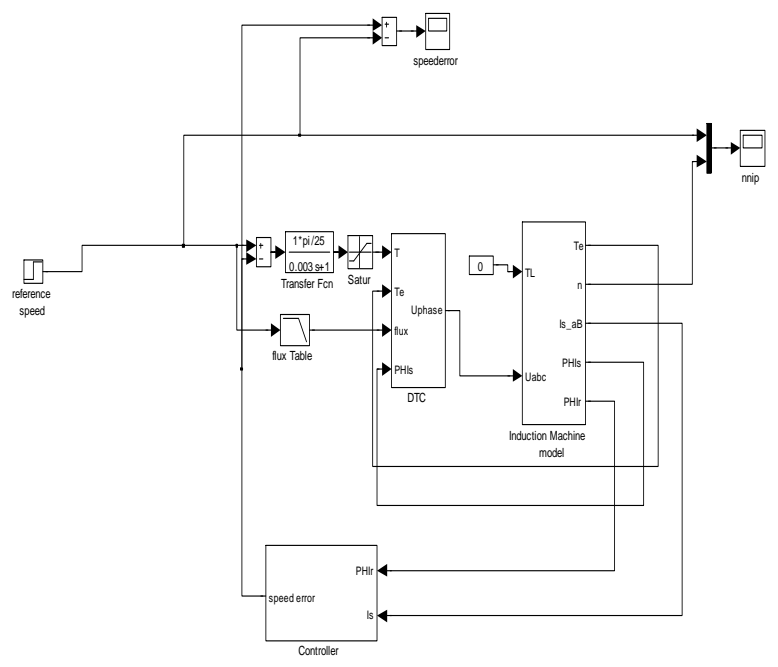

Fig 2: Simulink Diagram of DTC

\section{INDUCTION MOTOR MODEL}

Heart of this system is Induction machine model, it has two inputs they are controlled phase voltage from DTC and load torque. The outputs of induction machine model are torque, speed, stator current, stator flux and rotor flux. Parameters of Induction machine model are

TABLE1. IM Model Parameters

\begin{tabular}{|c|c|c|}
\hline S.No & Parameter & Value \\
\hline 1. & $\mathrm{R}_{\mathrm{r}}$ & 2.23 \\
\hline 2. & $\mathrm{~L}_{\mathrm{s}}$ & 0.3562 \\
\hline 3. & $\mathrm{~J}$ & 0.00825 \\
\hline 4. & $\mathrm{R}_{\mathrm{s}}$ & 2.7 \\
\hline 5. & $\mathrm{~L}_{\mathrm{r}}$ & 0.3562 \\
\hline 6. & $\mathrm{p}$ & 4 \\
\hline 7. & $\mathrm{~L}_{\mathrm{m}}$ & 0.3425 \\
\hline 8. & Pole Pairs & 2 \\
\hline
\end{tabular}

Three phase voltage is converted to two phase voltage by using following equations [ $3 \& 4]$

$$
\begin{gathered}
\mathrm{V}_{\mathrm{q}}=(2 / 3) \mathrm{V}_{\mathrm{as}}-(1 / 3) \mathrm{V}_{\mathrm{bs}}-(1 / 3) \mathrm{V}_{\mathrm{cs}}=\mathrm{V}_{\mathrm{as}} \\
\mathrm{V}_{\mathrm{d}}=-(1 / \sqrt{ } 3) \mathrm{V}_{\mathrm{bs}}+(1 / \sqrt{ } 3) \mathrm{V}_{\mathrm{cs}}
\end{gathered}
$$

Like two phase voltage we will get from this is called as D-Q model. Flux is directly proportional to the current but here flux is in differential form so the produced flux was integrated to get the stator current and rotor current. These currents are like $I_{s d}, I_{s q}, I_{r d}$ and $I_{r q}$. Following is the relation between flux and current

$$
\mathrm{N} \Phi=\mathrm{L} \mathrm{I}
$$

From this currents we will gets the torque value from the following equation [6]. 


$$
T_{e}=n p L_{m}\left(I_{r d} * I_{s q}-I_{s d} * I_{r q}\right)
$$

This torque is compared with load torque and multiplied with $\mathrm{np} / \mathrm{J}$ and integrated to get the motor speed in $\mathrm{rad} / \mathrm{sec}[5]$.

$$
\omega_{r}=\frac{P}{J}\left(T_{e}-T_{\text {load }}\right)
$$

From above equation we will gets the speed in $\mathrm{rad} / \mathrm{sec}$ and this is converted to speed (n) in rpm by multiplying with (np*60) / $(2 * \Pi)$.This speed feds to the matrix $\mathrm{A}_{1}$ from this speed with currents gives the flux again same process will starts.

Stator current, stator flux and rotor flux are gets from the following equations [8].

$$
\begin{aligned}
& \mathrm{Is}_{\mathrm{ab}}=\mathrm{I}_{\mathrm{sd}}+\mathrm{I}_{\mathrm{sq}} \\
& \mathrm{PHI}_{\mathrm{s}}=\Phi_{\mathrm{sd}}+\Phi_{\mathrm{s}} \\
& \mathrm{PHI}_{\mathrm{r}}=\Phi_{\mathrm{rd}}+\Phi_{\mathrm{rq}}
\end{aligned}
$$

where,

$$
\begin{gathered}
\Phi_{\mathrm{sd}}=\mathrm{I}_{\mathrm{sd}} \mathrm{L}_{\mathrm{s}}+\mathrm{I}_{\mathrm{rd}} \mathrm{L}_{\mathrm{m}} \\
\Phi_{\mathrm{sq}}=\mathrm{I}_{\mathrm{sq}} \mathrm{L}_{\mathrm{s}}+\mathrm{I}_{\mathrm{rr}} \mathrm{L}_{\mathrm{m}} \\
\Phi_{\mathrm{rd}}=\mathrm{I}_{\mathrm{rd}} \mathrm{L}_{\mathrm{s}}+\mathrm{I}_{\mathrm{sd}} \mathrm{L}_{\mathrm{m}} \\
\Phi_{\mathrm{rq}}=\mathrm{I}_{\mathrm{rq}} \mathrm{L}_{\mathrm{s}}+\mathrm{I}_{\mathrm{sq}} \mathrm{L}_{\mathrm{m}}
\end{gathered}
$$

\section{A. DTC Simulink Model}

In this four inputs are given to the table and the output of the table which controls the switches of the inverter. In this table stator flux and reference flux are compared and gives to relay to get the error in flux. Torque reference and motor torques are compared and gives to the torque hysteresis. In torque hysteresis logical signals are generated which is useful in decrease the noise and increases the switching on-off operations.

And stator flux is converted from two phase to three phase and this three phase stator flux, error in flux and error torque are gives to the subsystem. In subsystem logically switching states are designed that is on off switch positions of inverter and these are gives to the DTC switching table. This table controls the inverter. Fig.3 shows the level inverter which is main block of DTC.

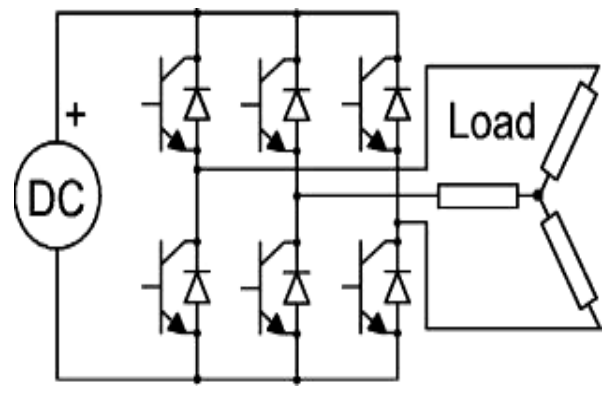

Fig 3: 3 Level Inverter

The DTC switching table with transport delay was given to the inverter. In inverter natural voltage was multiplied with 400 DC voltage and here natural to phase conversion matrix was used to get the controlled AC three phase voltage will come as output. Like this controlled phase voltage will gets which controls the induction machine model.

\section{B. Controller}

By using the stator current and rotor flux was used to control the speed of the induction machine model and these are the inputs to the controllers and speed error as the output we will get which control the speed of the induction machine model

\section{- Proportional \& Integral Controller}

For this controller stator current and rotor flux are the inputs and speed related with these input equations are developed in this controller Simulink model. The following are the equations used to develop the speed error as output from the controller [7].

$$
\begin{aligned}
& \dot{\Phi} d r=\frac{-1}{T r} \Phi d r+\frac{L m}{T r} \mathrm{I} d s-\omega r \Phi q r \\
& \dot{\Phi} q r=\frac{-1}{T r} \Phi q r+\frac{L m}{T r} \mathrm{I} q s+\omega r \Phi d r
\end{aligned}
$$

By adding above two equations we will get

$$
\dot{\Phi} r=\frac{L m}{T r} \mathrm{I} s-\frac{1}{T r} \Phi r+\omega r(\Phi q r-\Phi d r)
$$

For angular speed

$$
\begin{aligned}
& \omega r=K_{1} \int(\Phi r q \hat{\Phi} r d-\Phi r d \hat{\Phi} r q) d t+ \\
& K_{2}(\Phi r q \hat{\Phi} r d-\Phi r d \hat{\Phi} r q)
\end{aligned}
$$

With the help of these equations PI controller Simulink model was designed. 


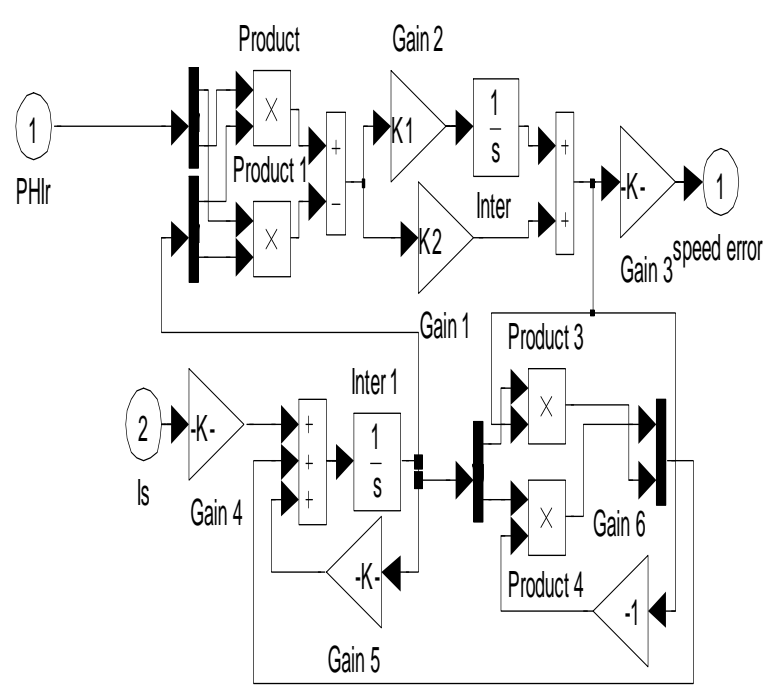

Fig 4: PI Controller Simulink Model

\section{- Neural Network Controller}

Using Back Propagation algorithm Neural Network was trained with example which is given in MATLAB NN design. Following figure shows the complete structural blocks of the Neural Network controller.

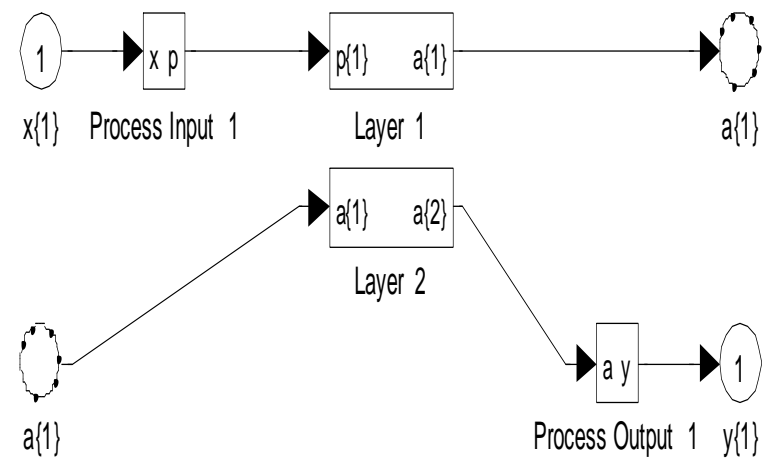

Fig 5: NN Controller Simulink Model

\section{RESULTS}

The induction motor model is simulated and wave forms are studied to have the following conclusions. In this model the load reference speed is $50 \mathrm{rpm}$ for the first 0.01 seconds, the reference speed then raised to $500 \mathrm{rpm}$ thereafter. The load torque maintained at $0 \mathrm{~N}-\mathrm{M}$. The response of Direct Torque Control System Using PI controller and NN controller is shown in Fig 6 \& 7. and comparison of these two controllers is also shown in Fig 8. The response in the figure 8 shows that with NN controller the maximum peak overshoot, oscillations, settling time is reduced and has attained good stability.

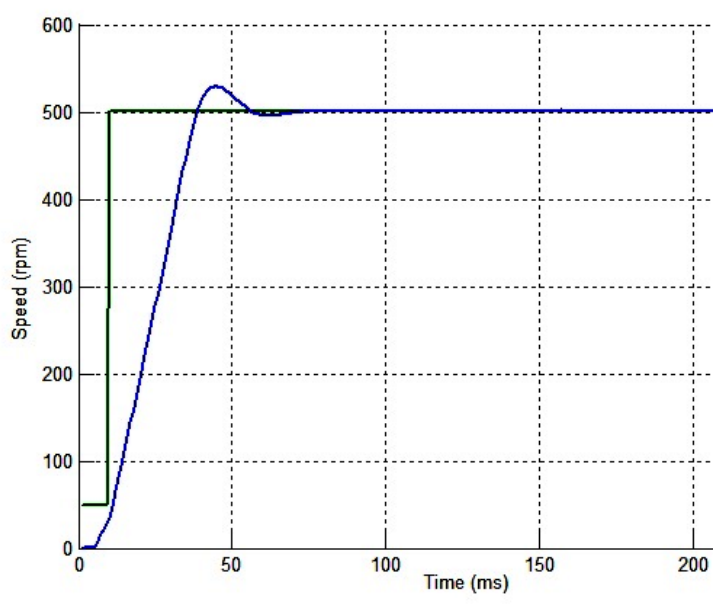

Fig 6: Response of PI Controller.

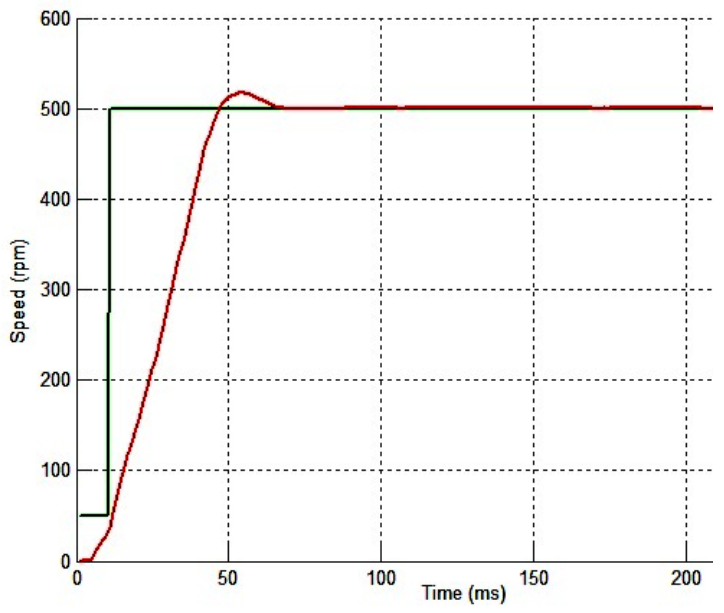

Fig 7: Response of NN Controller.

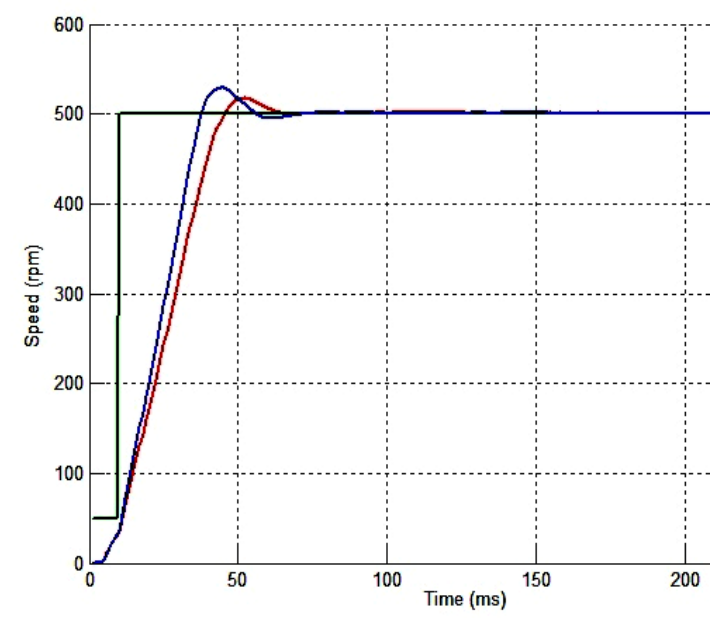

Fig 8: Comparison of PI with NN controller. 


\section{CONCLUSIONS}

Direct Torque Control System Using a Neural Network is successfully implemented on three phase induction motor. In this work, using the MATLAB simulation, a robustly stable speed controller for the induction motor system using the NN observer is presented. A high power 3-level fed induction motor with direct torque control system is developed. To cope with the inherent uncertainties such as parametric uncertainty, external disturbance and unmodeled dynamics, the $\mathrm{NN}$ is used as an uncertainty observer.

It approximates the inherent uncertainties. The proposed control algorithm is relatively simple and requires no restrictive conditions on the design constants for the stability. The speed controller response for induction motor using PI controller is shown and this is compared with the response of $\mathrm{NN}$ controller. It has been observed that the scheme proposed using $\mathrm{NN}$ is better than the PI controller scheme.

In future various kinds of control or motor systems such as vector control and PM synchronous motors can be applied with this approach.

\section{REFERENCES}

[1]. B.Heber and L.Xu (1997) "Fuzzy logic enhanced speed control of an indirect field-oriented induction machine drive", Vol.- 12, No 1, Page 772-778.

[2]. K.B.Lee and J.H.Song and I.Choy and J.Y.Yoo (2002) "Torque ripple reduction in DTC of induction motor driven by 3-Level inverter with low switching frequency", Vol.- 17, No 2, Page 255-264.

[3]. Riad TOUFOUTI and Salima MEZIANE and Hocine BENALLA (2007) "Direct Torque Control Strategy Of Induction Motors" University Mentouri, Vol.- 7,No 1.

[4]. R.Toufouti and S.Meziane and H. Benalla (2007) "DTC For Iunduction Motor Using Intelligent Techniques". University Constantine Algeria.

[5]. K.S.Sandhu and Vivek Pahwa (2009) "Simulation Study Of Three Phase Induction Motor with Variations In Moment of Ineritia", Vol.- 4, No 6, NIT Haryana, India.

[6]. K.L.SHI and T.F.CHAN and Y.K.WONG and S.L.HO(1999) "Modeling and Simulation Of Three Phase Induction Motor Using Simulink", Vol.- 36, Page 163-172, Polytechnic University, Hong Kong.

[7]. H.Kraiem, M.Ben Hamed, L. Sbita and M. Naceur Abdelkrim (2008) "DTC Sesnsorless Induction Motor Drives based on MRAS Simultanious Estimation of Rotor Speed And Stator Resistance", Vol.- 2, No 5, Page 306-313, National School of Engineering of Gabes(ENIG), Tunisia.

[8]. Karnopp, "Understanding Induction Motor State Equations Using Bond Graphs", University of California, Davis.

[9]. Brijesh Singh and Surya Prakash and Ajay Shekhar Pandey and S.K. Sinha (2010) "Intelligent PI Controller for Speed Control of D.C. Motor", Vol.- 2, No 1, Page 87-100, India. 